\title{
ANALISIS TINGKAT KEPUASAN KONSUMEN TERHADAP KUALITAS PRODUK DAN KUALITAS PELAYANAN DI RESTORAN CEPAT SAJI MCDONALD'S CABANG ROBINSON, DENPASAR
}

\author{
Gede Paramananda Jentrasaswin ${ }^{1}$, A.A.P.Agung Suryawan Wiranatha ${ }^{2}$, I Ketut Satriawan ${ }^{2}$ \\ ${ }^{1}$ Mahasiswa Jurusan Teknologi Industri Pertanian Fakultas Teknologi Pertanian UNUD \\ ${ }^{2}$ Dosen Jurusan Teknologi Industri Pertanian Fakultas Teknologi Pertanian UNUD \\ Email koresponden: agung_suryawan@unud.ac.id
}

\begin{abstract}
Product quality and services have been the most concern of the trade and service. One of the efforts that can be used to improve and maintain the competitiveness of a company is to increase consumer satisfaction. The objectives of this study were 1) to determine the level of consumer interest in the products and services provided by McDonald's, 2) to analyze the performance of McDonalds company in giving satisfaction to consumer, and 3) to analyze the level of customer satisfaction on products and services. Data collection in this study was done by distributing 255 questionnaires to consumers. Importance Performance Analysis method was used to analyse the effect of quality of the product \& service on consumer satisfaction. The results show that consumers were satisfied on the product quality and service provided. The level of consumer satisfaction was $84,64 \%$ (satisfied) for the product quality and $83,06 \%$ (satisfied) for the service quality.
\end{abstract}

Keywords: Costumer satisfaction, importance performance analysis, McDonald's

\section{Latar Belakang}

\section{PENDAHULUAN}

Perkembangan perusahaan makanan pada saat sekarang ini memang cukup pesat. Hal ini disebabkan karena manusia tidak dapat melepaskan kebutuhannya untuk makan karena hanya dengan makan manusia dapat terus melangsungkan hidupnya. Hal inilah yang menjadi penyebab adanya persaingan sesama perusahaan makanan, karena sama-sama ingin memberikan yang terbaik dan masing-masing mempunyai keunggulan dalam produknya. Salah satu usaha dalam persaingan adalah meningkatkan kepuasan konsumen dan perusahaan harus mencurahkan perhatiannya pada hal-hal yang dianggap penting oleh konsumen. Kepuasan adalah perasaan senang atau kecewa seseorang yang berasal dari perbandingan antara kesan terhadap hasil suatu produk dengan harapan-harapannya (Kotler, 2005). Kepuasan konsumen adalah keseluruhan penilaian dari suatu pengalaman pembelian dan konsumsi atas barang maupun jasa (Anderson et al., 1994).

Restoran cepat saji McDonald's adalah salah satu restoran cepat saji terpopuler di dunia termasuk di Indonesia. Dalam upaya peningkatan kepuasan konsumen terhadap produk dan jasa pelayanan yang diberikan, maka perlu melakukan penelitian yang bertujuan untuk mengetahui sejauh mana konsumen merasa puas dalam menikmati produk dan jasa pelayanan yang diberikan oleh perusahaan McDonald's yang ada di Bali. Selain itu, sebagai bahan evaluasi terhadap program usaha perusahaan sehingga dapat digunakan sebagai bahan pertimbangan dalam menentukan kebijakan di masa yang akan datang. 


\section{BAHAN DAN METODE}

Penelitian ini dimulai dengan studi literatur tentang tingkat kepuasan konsumen terhadap kualitas produk dan kualitas pelayanan yang diberikan perusahaan. Kemudian dilanjutkan dengan perumusan masalah dan tujuan penelitian, serta pembuatan kuisioner dan validitas dan reliabilitas kuisioner. Penelitian ini menggunakan 255 konsumen di Restoran McDonald's cabang Robinson yang bertempat di Jalan P.B. Sudirman, Denpasar sebagai responden berdasarkan perhitungan Metode Slovin (Sevilla, 1993) dengan tingkat kesalahan 5\%. Responden adalah konsumen yang pernah mengkonsumsi produk dari perusahaan tersebut. Penilaian terhadap konsumen pada penelitian ini menggunakan skala likert (Mulyatiningsih, 2012). Skala Likert digunakan untuk mengukur sikap, pendapat, dan persepsi seseorang atau sekelompok orang tentang fenomena sosial. Pengumpulan data dilakukan di Restoran McDonald's pada bulan Januari 2018 dalam kurun waktu 1 minggu. Analisis data dilakukan dengan Metode Importance Performance Analysis, yaitu sebuah teknik analisis yang digunakan untuk mengidentifikasi faktor-faktor kinerja apa yang harus ditunjukkan oleh suatu organisasi dalam memenuhi kepuasan para pengguna jasa mereka (konsumen) (Martilla dan James, 1977). Selain itu digunakan juga untuk mengetahui pengaruh secara simultan antara kualitas produk dan jasa pelayanan terhadap tingkat kepuasan konsumen.

Setelah seluruh data dan informasi berhasil dikumpulkan maka dilakukan tabulasi data dan mengintepretasi data tersebut sebagai berikut:

1. Uji validitas kuisioner menggunakan teknik Product Moment. Uji reliabilitas dalam penelitian ini menggunakan metode Cronbach Alpha (Singarimbun dan Effendi, 1989).

2. Importance Performance Analysis menggunakan diagram kartesius merupakan suatu bangun yang dibagi atas empat bagian yang dibatasi oleh dua buah garis yang berpotongan tegak lurus pada titik-titik $(\mathrm{X}),(\mathrm{Y})$, dimana $\mathrm{X}$ merupakan rata-rata dari skor tingkat kepuasan karyawan dan $\mathrm{Y}$ adalah rata-rata dari skor tingkat kepentingan seluruh variabel. Tingkat kepuasan konsumen merupakan hasil perbandingan skor kepuasan dengan skor kepentingan. Rata-rata penilaian kepentingan dan kepuasan konsumen dibagi menjadi empat bagian ke dalam diagram kartesius, yaitu :

- Kuadran A : menunjukan variabel-variabel kompensasi yang perlu diprioritas utamakan oleh perusahaan.

- Kuadran B : menunjukan variabel yang dirasa sangat penting dan konsumen sudah merasa puas.

- Kuadran C : adalah variabel yang dianggap penting oleh konsumen dan kepuasannya sudah dirasa cukup puas oleh konsumen.

- Kuadran D : adalah variabel-variabel yang dianggap penting dan sudah dijalankan dengan baik namun dinilai berlebihan karena nilai kesenjangannya yang rendah. 
Tabel 1. Skala likert

\begin{tabular}{ccc}
\hline Keterangan & Skor & Rentang \\
\hline Tidak Puas/Tidak Penting & 1 & $1,00-1,80$ \\
Kurang Puas/Kurang Penting & 2 & $1,81-2,60$ \\
Biasa & 3 & $2,61-3,40$ \\
Puas/Penting & 4 & $3,41-4,20$ \\
Sangat Puas/Sangat Penting & 5 & $4,21-5,00$ \\
\hline
\end{tabular}

\section{HASIL DAN PEMBAHASAN}

\section{Gambaran Umum Perusahaan}

Restoran cepat saji McDonald's cabang Robinson Denpasar adalah salah satu perusahaan franchise McDonald's yang berlokasi di Jalan P.B. Sudirman, Denpasar. Restoran ini berdiri sekitar awal tahun 2000. Produk yang disajikan pun semakin bervariasi demi meningkatkan kepuasan konsumen. Saat ini Restoran McDonald's cabang Robinson telah mempekerjakan sebanyak 40 orang pegawai untuk memenuhi kebutuhan konsumen selama 24 jam setiap harinya.

\section{Pengujian Kuisioner (Uji Validitas dan Reliabilitas)}

Hasil pengukuran validitas kuisioner menggunakan analisis Product Moment, didapatkan bahwa nilai $r$ pada setiap penyataan pada setiap kuisioner menunjukan nilai di atas $r$ tabel $(\alpha=0,5)$ sebesar 0,349. Hasil pengukuran reliabilitas kuisioner kepentingan dan kepuasan dengan menggunakan metode Alpha Cronbach didapatkan koefisien alpha $(\alpha)$ sebesar 0,892 dan 0,838 sedangkan $r$ tabel $(\alpha=0,468)$.

\section{Tingkat Kepentingan Terhadap Masing-Masing Variabel}

Pada tabel di tingkat kepentingan konsumen (Tabel 2) dapat diketahui variabel yang mempunyai total skor terendah adalah pelayanan perusahaan ketika konsumen membutuhkan sesuatu, karyawan McDonald's selalu memiliki waktu luang untuk membantu konsumen dengan nilai rata-rata 3,87 (Puas). Skor tertinggi adalah karyawan McDonald's mampu memberikan produk sesuai pesanan yang diminta yaitu dengan nilai rata-rata 4,52 (Sangat Puas).

Tabel 2. Hasil total skor tingkat kepentingan terhadap masing-masing variabel

\begin{tabular}{|c|c|c|c|c|c|c|c|c|}
\hline No & Variabel & STP & TP & B & $\mathrm{P}$ & SP & Total & Rerata \\
\hline \multicolumn{9}{|c|}{ Kualitas Produk } \\
\hline 1 & Produk yang disajikan sangat lezat & - & - & 120 & 500 & 450 & 1,070 & 4.19 \\
\hline 2 & Produk yg disajikan selalu fresh & - & - & 165 & 468 & 415 & 1,048 & 4.11 \\
\hline 3 & Rasa produk yang disajikan sesuai selera konsumen & - & - & 60 & 504 & 545 & 1,109 & 4.34 \\
\hline 4 & $\begin{array}{l}\text { Produk yang disajikan bersih dan bebas dari kotoran } \\
\text { maupun kuman }\end{array}$ & - & - & 96 & 516 & 470 & 1,082 & 4.24 \\
\hline 5 & Produk yang disajikan tidak mudah basi & - & - & 51 & 552 & 500 & 1,103 & 4.32 \\
\hline \multirow[t]{3}{*}{6} & $\begin{array}{l}\text { Rasa produk yang disajikan sesuai dengan lidah } \\
\text { masyarakat Indonesia }\end{array}$ & - & - & 150 & 472 & 435 & 1,057 & 4.14 \\
\hline & Rata-rata $=$ & & & & & & & 4.22 \\
\hline & Kualitas Pelayanan & & & & & & & \\
\hline
\end{tabular}


7 Karyawan McDonald's mampu memberikan produk sesuai pesanan yang diminta

8 Karyawan McDonald's cekatan dalam menangani kebutuhan akan pesanan konsumen

9 Ketika konsumen membutuhkan sesuatu, karyawan McDonald's memiliki waktu luang untuk membantu konsumen

10 Karyawan McDonald's memiliki pengetahuan tentang produk yang dipesan

11 Konsumen merasa nyaman saat berbelanja di McDonald's

12 Karyawan McDonald's selalu bersikap sopan dan sabar kepada konsumen

13 Karyawan McDonald's memberikan pelayanan yang sama tanpa memandang status sosial

14 Restoran McDonald's memiliki jam buka yang sesuai dengan keinginan konsumen

15 Restoran McDonald's memiliki tempat yang nyaman

16 Lokasi Restoran McDonald's mudah untuk ditemukan

17 Konsumen tidak terlalu lama mengantri dalam membeli produk

18 Konsumen merasa puas dengan kesopanan yang dimiliki oleh karyawan Restoran McDonald's

19 Konsumen merasa puas dengan keramahan yang dimiliki oleh karyawan Restoran McDonald's

20 Konsumen merasa puas dengan keamanan, kenyamanan dan kebersihan outlet Restoran McDonald's

\section{Tingkat Kepuasan Terhadap Masing-Masing Variabel}

Pada penelitian ini didapatkan tingkat kepuasan konsumen seperti pada Tabel 3. Variabel yang mempunyai skor terendah adalah kenyamanan restoran McDonald's dengan nilai rata-rata 3,67 (Puas). Variabel yang memiliki skor tertinggi adalah karyawan McDonald's mampu memberikan produk sesuai pesanan yang diminta yaitu dengan nilai rata-rata 4,61 (Sangat Puas).

Tabel 3. Hasil total skor tingkat kepuasan terhadap masing-masing variabel

\begin{tabular}{|c|c|c|c|c|c|c|c|c|}
\hline No & Variabel & STP & $\mathrm{TP}$ & $\mathrm{B}$ & $\mathrm{P}$ & SP & Total & Rerata \\
\hline \multicolumn{9}{|c|}{ Kualitas Produk } \\
\hline 1 & Produk yang disajikan sangat lezat & - & - & 105 & 452 & 535 & 1,092 & 4.28 \\
\hline 2 & Produk yg disajikan selalu fresh & - & - & 150 & 480 & 425 & 1,055 & 4.13 \\
\hline 3 & Rasa produk yang disajikan sesuai selera konsumen & - & - & 81 & 460 & 565 & 1,106 & 4.33 \\
\hline 4 & $\begin{array}{l}\text { Produk yang disajikan bersih dan bebas dari kotoran } \\
\text { maupun kuman }\end{array}$ & - & 4 & 66 & 508 & 520 & 1,098 & 4.31 \\
\hline 5 & Produk yang disajikan tidak mudah basi & - & 10 & 141 & 340 & 590 & 1,081 & 4.23 \\
\hline \multirow[t]{3}{*}{6} & $\begin{array}{l}\text { Rasa produk yang disajikan sesuai dengan lidah } \\
\text { masyarakat Indonesia }\end{array}$ & - & - & 138 & 528 & 385 & 1,051 & 4.12 \\
\hline & Rata-rata $=$ & & & & & & & 4.23 \\
\hline & \multicolumn{8}{|l|}{ Kualitas Pelayanan } \\
\hline 7 & $\begin{array}{l}\text { Karyawan McDonald's mampu memberikan produk sesuai } \\
\text { pesanan yang diminta }\end{array}$ & - & - & 63 & 224 & 890 & 1,177 & 4.61 \\
\hline 8 & $\begin{array}{l}\text { Karyawan McDonald's cekatan dalam menangani } \\
\text { kebutuhan akan pesanan konsumen }\end{array}$ & - & - & - & 496 & 655 & 1,151 & 4.51 \\
\hline
\end{tabular}


9 Ketika konsumen membutuhkan sesuatu, karyawan McDonald's memiliki waktu luang untuk membantu konsumen

10 Karyawan McDonald's memiliki pengetahuan tentang produk yang dipesan

11 Konsumen merasa nyaman saat berbelanja di McDonald's

12 Karyawan McDonald's selalu bersikap sopan dan sabar kepada konsumen

13 Karyawan McDonald's memberikan pelayanan yang sama tanpa memkonsumenng status sosial

14 Restoran McDonald's memiliki jam buka yang sesuai dengan keinginan konsumen

15 Restoran McDonald's memiliki tempat yang nyaman

16 Lokasi Restoran McDonald's mudah untuk ditemukan

17 Konsumen tidak terlalu lama mengantri dalam membeli produk

18 Konsumen merasa puas dengan kesopanan yang dimiliki oleh karyawan Restoran McDonald's

19 Konsumen merasa puas dengan keramahan yang dimiliki oleh karyawan Restoran McDonald's

20 Konsumen merasa puas dengan keamanan, kenyamanan dan kebersihan outlet Restoran McDonald's

\begin{tabular}{|c|c|c|c|c|}
\hline 258 & 428 & 310 & 996 & 3.91 \\
\hline 51 & 528 & 530 & 1,109 & 4.34 \\
\hline 192 & 568 & 245 & 1,005 & 3.94 \\
\hline 105 & 436 & 555 & 1,096 & 4.29 \\
\hline 84 & 516 & 490 & 1,090 & 4.27 \\
\hline 291 & 396 & 295 & 982 & 3.85 \\
\hline 369 & 200 & 340 & 937 & 3.67 \\
\hline 129 & 568 & 350 & 1,047 & 4.11 \\
\hline 291 & 300 & 385 & 988 & 3.87 \\
\hline 162 & 428 & 470 & 1,060 & 4.15 \\
\hline 123 & 488 & 460 & 1,071 & 4.21 \\
\hline 96 & 336 & 640 & 1,094 & 4.29 \\
\hline
\end{tabular}

\section{Pengukuran Indeks Kepuasan Konsumen}

Perhitungan indeks kepuasan konsumen terhadap kualitas produk dapat dilihat pada Tabel 4. Nilai total skor adalah total hasil perkalian antara rata-rata tingkat kepentingan dengan rata-rata tingkat kepuasan

Tabel 4. Hasil perhitungan indeks kepuasan konsumen Restoran McDonald's

\begin{tabular}{|c|c|c|c|c|c|}
\hline No & Variabel & $\begin{array}{l}\text { Kepentingan } \\
\text { (Y) }\end{array}$ & $\begin{array}{l}\text { Kepuasan } \\
(\mathrm{X})\end{array}$ & $\begin{array}{l}\text { Skor } \\
(\mathrm{Y} . \mathrm{X})\end{array}$ & $\begin{array}{l}\text { Persentase } \\
\quad(\%)\end{array}$ \\
\hline \multicolumn{6}{|c|}{ Kualitas Produk } \\
\hline $\mathrm{X} 1$ & Produk yang disajikan sangat lezat & 4.19 & 4.28 & 17.93 & 102.05 \\
\hline $\mathrm{X} 2$ & Produk yg disajikan selalu fresh & 4.1 & 4.13 & 16.93 & 100.66 \\
\hline $\mathrm{X} 3$ & Rasa produk yang disajikan sesuai selera konsumen & 4.34 & 4.33 & 18.79 & 99.72 \\
\hline $\mathrm{X} 4$ & $\begin{array}{l}\text { Produk yang disajikan bersih dan bebas dari kotoran } \\
\text { maupun kuman }\end{array}$ & 4.24 & 4.3 & 18.23 & 101.47 \\
\hline $\mathrm{X} 5$ & Produk yang disajikan tidak mudah basi & 4.32 & 4.23 & 18.27 & 98.01 \\
\hline \multirow[t]{3}{*}{ X6 } & $\begin{array}{l}\text { Rasa produk yang disajikan sesuai dengan lidah masyarakat } \\
\text { Indonesia }\end{array}$ & 4.14 & 4.12 & 17.05 & 99.43 \\
\hline & Skor Total $\left(\sum\right)$ & 25.33 & 25.39 & 107.2 & 601.34 \\
\hline & Rata-rata & 4.22 & 4.23 & 17.87 & 100.22 \\
\hline
\end{tabular}

Sedangkan untuk perhitungan indeks kepuasan konsumen terhadap kualitas pelayanan dapat dilihat pada Tabel 5 . 
Tabel 5. Hasil perhitungan indeks kepuasan konsumen Restoran McDonald's

\begin{tabular}{|c|c|c|c|c|c|}
\hline \multicolumn{5}{|c|}{ Kualitas Pelayanan } & \multirow[b]{2}{*}{102.08} \\
\hline $\mathrm{X} 7$ & $\begin{array}{l}\text { Karyawan McDonald's mampu memberikan produk sesuai pesanan yang } \\
\text { diminta }\end{array}$ & 4.52 & 4.61 & 20.83 & \\
\hline $\mathrm{X} 8$ & $\begin{array}{l}\text { Karyawan McDonald's cekatan dalam menangani kebutuhan akan pesanan } \\
\text { konsumen }\end{array}$ & 4.46 & 4.51 & 20.11 & 101.05 \\
\hline $\mathrm{X} 9$ & $\begin{array}{l}\text { Ketika konsumen membutuhkan sesuatu, karyawan McDonald's memiliki } \\
\text { waktu luang untuk membantu konsumen }\end{array}$ & 3.87 & 3.9 & 15.09 & 100.7 \\
\hline $\mathrm{X} 10$ & Karyawan McDonald's memiliki pengetahuan tentang produk yang dipesan & 4.4 & 4.34 & 19.09 & 98.66 \\
\hline $\mathrm{X} 11$ & Konsumen merasa nyaman saat berbelanja di McDonald's & 4.32 & 3.94 & 17.02 & 91.11 \\
\hline $\mathrm{X} 12$ & Karyawan McDonald's selalu bersikap sopan dan sabar kepada konsumen & 4.31 & 4.29 & 18.48 & 99.63 \\
\hline $\mathrm{X} 13$ & $\begin{array}{l}\text { Karyawan McDonald's memberikan pelayanan yang sama tanpa memandang } \\
\text { status social }\end{array}$ & 4.19 & 4.27 & 17.89 & 101.86 \\
\hline $\mathrm{X} 14$ & $\begin{array}{l}\text { Restoran McDonald's memiliki jam buka yang sesuai dengan keinginan } \\
\text { konsumen }\end{array}$ & 3.89 & 3.85 & 14.97 & 98.99 \\
\hline $\mathrm{X} 15$ & Restoran McDonald's memiliki tempat yang nyaman & 3.9 & 3.67 & 14.31 & 94.17 \\
\hline $\mathrm{X} 16$ & Lokasi Restoran McDonald's mudah untuk ditemukan & 3.91 & 4.1 & 16.03 & 104.9 \\
\hline $\mathrm{X} 17$ & Konsumen tidak terlalu lama mengantri dalam membeli produk & 3.88 & 3.87 & 15.01 & 99.69 \\
\hline $\mathrm{X} 18$ & $\begin{array}{l}\text { Konsumen merasa puas dengan kesopanan yang dimiliki oleh karyawan } \\
\text { Restoran McDonald's }\end{array}$ & 4.15 & 4.15 & 17.22 & 100 \\
\hline $\mathrm{X} 19$ & $\begin{array}{l}\text { Konsumen merasa puas dengan keramahan yang dimiliki oleh karyawan } \\
\text { Restoran McDonald's }\end{array}$ & 4.15 & 4.2 & 17.43 & 101.03 \\
\hline \multirow[t]{3}{*}{$\mathrm{X} 20$} & $\begin{array}{l}\text { Konsumen merasa puas dengan keamanan, kenyamanan dan kebersihan outlet } \\
\text { Restoran McDonald's }\end{array}$ & 4.21 & 4.29 & 18.06 & 101.86 \\
\hline & Skor Total $\left(\sum\right)$ & 58.16 & 57.99 & 241.54 & 1395.73 \\
\hline & Rata-rata & 4.15 & 4.14 & 17.25 & 99.69 \\
\hline
\end{tabular}

Dari tabel tersebut dapat dihitung indeks kepuasan konsumen dengan rumus sebagai berikut:

Indeks Kepuasan Konsumen terhadap kualitas produk dan pelayanan :

$$
\begin{array}{ll}
\frac{\sum(\mathrm{X} . \mathrm{Y})}{5 \times Y} \times 100 \% & \frac{\sum(\mathrm{X} . \mathrm{Y})}{5 \times Y} \times 100 \% \\
=\frac{107.2}{5 \times 25.33} \times 100 \% & =\frac{241.54}{5 \times 58.16} \times 100 \% \\
=84,64 \% & =83,06 \%
\end{array}
$$

Berdasarkan hasil perhitungan indeks kepuasan konsumen sebesar 84,64\% terhadap kualitas produk dan sebesar 83,06\% terhadap kualitas pelayanan, maka sesuai dengan kriteria indeks kepuasan karyawan sebesar $80 \%$ atau lebih dari $80 \%$, hal ini mengindikasikan bahwa konsumen merasa puas terhadap kualitas produk dan kualitas pelayanan yang diberikan oleh restoran cepat saji McDonald's.

\section{Pengukuran Importance Performance Analysis}

Diagram kartesius tingkat kepuasan dan kepentingan konsumen terhadap kualitas produk Restoran McDonald's dapat dilihat pada gambar berikut: 


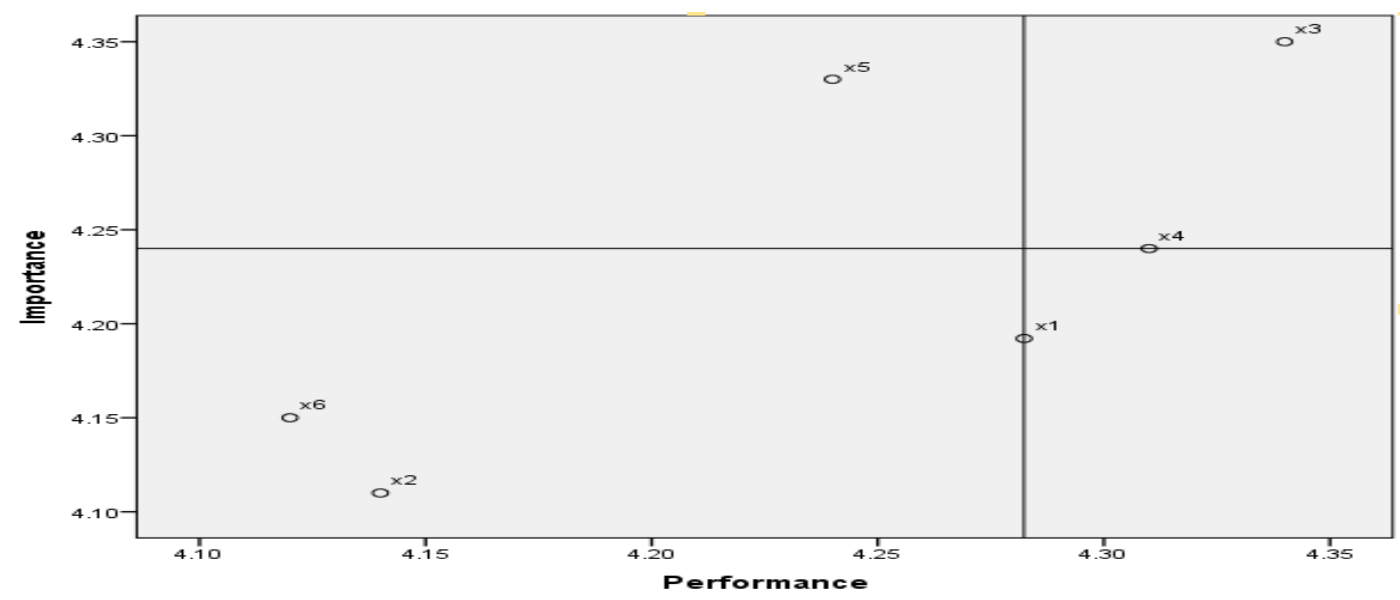

Gambar 1. Diagram kartesius tingkat kepuasan dan kepentingan konsumen terhadap kualitas produk

Restoran McDonald's

\section{Kuadran A (Prioritas Utama)}

Atribut-atribut yang berada di kuadran A merupakan atribut yang dianggap penting oleh responden. Namun kinerja yang diterima dalam pelaksanaannya dinilai kurang oleh konsumen. Atribut tersebut adalah produk yang disajikan tidak mudah basi (x5). Dalam hal ini berarti Restoran McDonald's harus meningkatkan kinerja atribut yang berada di kuadran ini dengan cara menyimpan produk makanan di dalam lemari penyimpanan dengan baik dan mengatur suhu penyimpanan sesuai prosedur agar bahan makanan tidak mudah basi sehingga mencapai harapan dari konsumen serta tercipta kepuasan konsumen yang diinginkan.

\section{Kuadran B (Prioritas Kedua)}

Atribut-atribut yang berada di kuadran B merupakan atribut yang dianggap penting oleh responden dan kinerja yang diterima dalam pelaksanaannya dinilai sudah sesuai dengan harapan konsumen. Atribut-atribut tersebut adalah produk memiliki rasa sesuai dengan selera konsumen (X3) dan produk yang disajikan bersih dan bebas dari kuman (X4). Hal ini berarti Restoran McDonald"s sudah melaksanakan atribut-atribut tersebut dengan baik sehingga tercapai kepuasan konsumen.

\section{Kuadran C (Prioritas Rendah)}

Atribut-atribut yang berada di kuadran C merupakan atribut yang dianggap kurang penting oleh responden dan kinerja yang diterima dalam pelaksanaannya juga biasa saja. Atribut-atribut tersebut adalah produk yang disajikan selalu fresh (X2) dan produk yang disajikan sesuai dengan lidah masyarakat Indonesia (X6). Hal ini berarti Restoran McDonald's harus meningkatkan kinerja dari atribut-atribut ini agar tercapai kepuasan maksimal dari konsumen.

\section{Kuadran D (Prioritas Sangat Rendah)}

Atribut-atribut yang berada di kuadran D merupakan atribut yang dianggap kurang penting oleh responden namun kinerja yang diterima dalam pelaksanaannya sudah sangat baik. Atribut tersebut adalah Restoran McDonald's memiliki produk dengan rasa yang sangat lezat (X1). Hal ini berarti Restoran McDonald's harus mempertahankan kinerja dari atribut ini namun jangan terlalu berlebihan 
dalam pelaksanaannya. Sedangkan diagram kartesius untuk tingkat kepuasan dan kepentingan konsumen terhadap kualitas pelayanan Restoran McDonald's dapat dilihat pada gambar berikut.

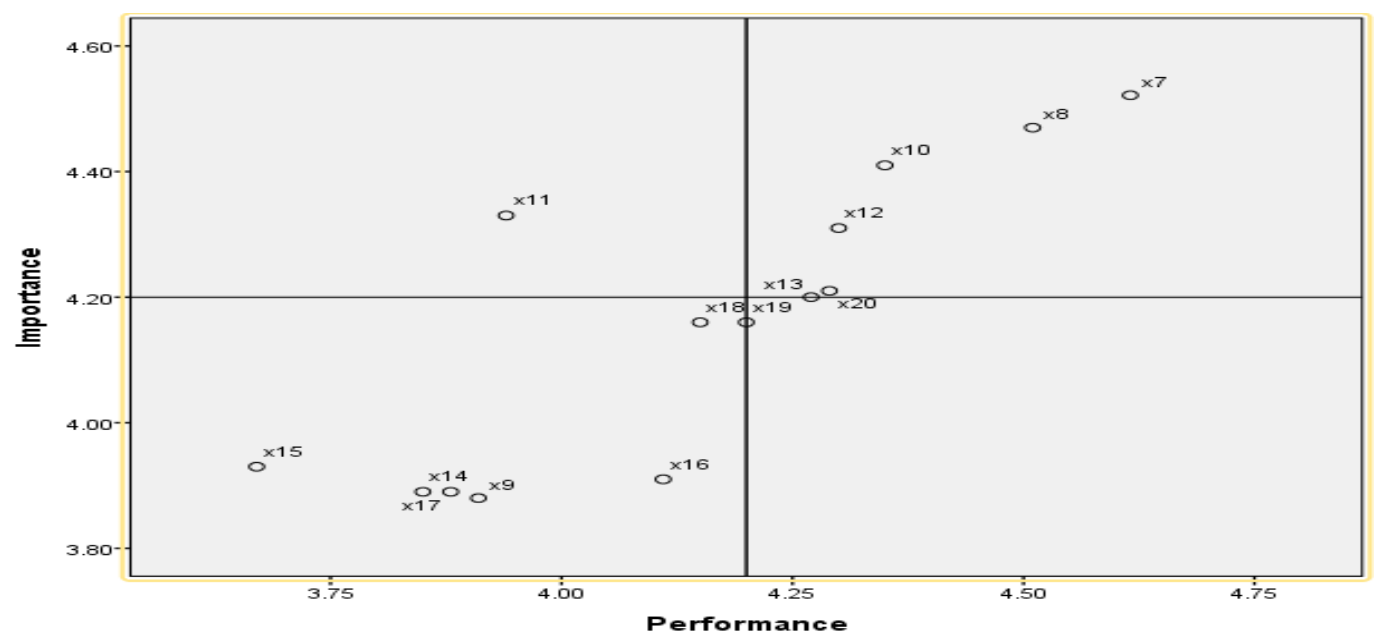

Gambar 2. Diagram kartesius tingkat kepuasan dan kepentingan konsumen terhadap kualitas pelayanan Restoran McDonald's

\section{Kuadran A (Prioritas Utama)}

Atribut-atribut yang berada di kuadran A merupakan atribut yang dianggap penting oleh responden. Namun kinerja yang diterima dalam pelaksanaannya dinilai kurang oleh konsumen. Atribut tersebut adalah konsumen merasa nyaman saat berbelanja di Restoran McDonald's (X11). Dalam hal ini berarti Restoran McDonald's harus meningkatkan kinerja atribut yang berada di kuadran ini bisa dengan meningkatkan segi kebersihan dan menambah jumlah karyawan untuk melayani permintaan konsumen secara optimal serta memperhatikan faktor penunjang lain seperti WiFi dan pendingin ruangan (Air Conditioner) sehingga tercapai kepuasan konsumen yang diinginkan.

\section{Kuadran B (Prioritas Kedua)}

Atribut-atribut yang berada di kuadran B merupakan atribut yang dianggap penting oleh responden dan kinerja yang diterima dalam pelaksanaannya dinilai sudah sesuai dengan harapan konsumen. Atribut-atribut tersebut meliputi produk yang diberikan sesuai dengan pesanan konsumen (X7), karyawan McDonald's cekatan dalam menangani kebutuhan konsumen (X8), karyawan memiliki pengetahuan tentang produk yang disajikan (X10), karyawan bersikap sopan dan sabar dalam melayani konsumen (X12) dan konsumen merasa puas dengan keamanan dan kebersihan outlet Restoran McDonald's (X20) . Hal ini berarti Restoran McDonald"s sudah melaksanakan atributatribut tersebut dengan baik sehingga tercapai kepuasan konsumen.

\section{Kuadran C (Prioritas Rendah)}

Atribut-atribut yang berada di kuadran $\mathrm{C}$ merupakan atribut yang dianggap kurang penting oleh responden dan kinerja yang diterima dalam pelaksanaannya juga biasa saja. Atribut-atribut tersebut meliputi karyawan memiliki waktu luang untuk membantu kebutuhan konsumen (X9), Restoran McDonald's memiliki jam buka sesuai dengan keinginan konsumen (X14), Restoran McDonald's memiliki tempat yang nyaman (X15), lokasi Restoran McDonald's mudah ditemukan (X16), 
konsumen tidak membutuhkan waktu lama dalam mengantri (X17) dan konsumen merasa puas dengan kesopanan para karyawan (X18). Hal ini berarti Restoran McDonald's sudah cukup baik dalam melaksanakan kinerja pada atribut tersebut tetapi harus tetap ditingkatkan agar tercapai kepuasan maksimal dari konsumen.

\section{Kuadran D (Prioritas Sangat Rendah)}

Atribut-atribut yang berada di kuadran D merupakan atribut yang dianggap kurang penting oleh responden namun kinerja yang diterima dalam pelaksanaannya sudah sangat baik. Atribut tersebut adalah konsumen merasa puas dengan keramahan yang dimiliki oleh karyawan Restoran McDonald's (X19) dan konsumen merasa puas dengan keamanan, kenyamanan dan kebersihan outlet Restoran McDonald's (X20). Hal ini berarti Restoran McDonald's harus mempertahankan kinerja dari atribut ini namun jangan terlalu berlebihan dalam pelaksanaannya.

\section{KESIMPULAN DAN SARAN}

\section{Kesimpulan}

Berdasarkan analisis yang telah dilakukan sebelumnya, dapat disimpulkan beberapa hal sebagai berikut :

1. Pada tingkat kepentingan terhadap kualitas produk, variabel yang mendapatkan skor tertinggi adalah rasa produk yang disajikan sesuai selera konsumen dengan nilai rata-rata 4,34 (Sangat Penting), sedangkan variabel yang mendapatkan nilai terendah adalah produk yang disajikan selalu fresh dengan nilai rata-rata 4,1 (Penting). Pada tingkat kepentingan terhadap kualitas pelayanan, variabel yang mempunyai total skor tertinggi adalah karyawan McDonald's mampu memberikan produk sesuai pesanan yang diminta dengan nilai rata-rata 4,52 (Sangat Penting). Sedangkan variabel yang memiliki skor terendah adalah ketika konsumen membutuhkan sesuatu, karyawan McDonald's selalu memiliki waktu luang untuk membantu konsumen dengan nilai rata-rata 3,87 (Penting).

Pada tingkat kinerja terhadap kualitas produk, variabel yang mempunyai skor tertinggi adalah rasa produk yang disajikan sesuai selera konsumen dengan nilai rata-rata 4,33 (Sangat Puas) dan variabel yang memiliki skor terendah adalah rasa produk yang disajikan sesuai dengan lidah masyarakat Indonesia dengan nilai rata-rata 4,12 (Puas). Pada tingkat kinerja terhadap kualitas pelayanan, variabel yang mendapatkan skor tertinggi adalah karyawan McDonald's mampu memberikan produk sesuai dengan pesanan yang diminta dengan nilai rata-rata 4,61 (Sangat Puas). Sedangkan variabel yang mendapat skor terendah adalah Restoran McDonald's memiliki tempat yang nyaman dengan nilai rata-rata 3,67 (Puas).

2. Berdasarkan hasil perhitungan indeks kepuasan konsumen sebesar $84,64 \%$ terhadap kualitas produk dan sebesar $83,06 \%$ terhadap kualitas pelayanan, maka sesuai dengan kriteria indeks kepuasan karyawan sebesar $80 \%$ atau lebih dari $80 \%$, hal ini mengindikasikan bahwa 
konsumen merasa puas terhadap kualitas produk dan kualitas pelayanan yang diberikan oleh restoran cepat saji McDonald's

3. Variabel yang perlu mendapatkan prioritas untuk dilakukan perbaikan dari Restoran McDonald's cabang Robinson berdasarkan tingkat kepentingan dan tingkat kepuasan konsumen adalah seluruh variabel yang berada di kuadran A, yaitu produk yang disajikan tidak mudah basi pada kualitas produk dan kenyamanan konsumen saat berbelanja di Restoran McDonald's pada kualitas pelayanan.

\section{Saran}

Perusahaan diharapkan untuk dapat mengevaluasi kepuasan konsumen dengan mengikuti hasil dari penelitian ini, yaitu dengan meningkatkan kepuasan konsumen dengan mempertimbangkan seluruh variabel yang masuk ke dalam kuadran A, yaitu produk yang disajikan tidak mudah basi serta kenyamanan konsumen saat berbelanja di Restoran McDonald's cabang Robinson demi meningkatkan kepuasan konsumen dalam berbelanja, sehingga Restoran McDonald's tersebut dapat berjalan lebih baik lagi.

\section{DAFTAR PUSTAKA}

Anderson, E. W., Fornell, C. and Lehmann, D. R. 1994. Customer Satisfaction, Market Share, and Profitability: Finding From Sweden. Journal of Marketing. Vol (58) : 53-56.

Kotler, P. 2005. Manajemen Pemasaran. Jilid II. Edisi Kesebelas. Alih Bahasa Benyamin Molan. Indeks, Jakarta.

Manik Iswari, I.A. 2015. Analisis Kepuasan Konsumen Terhadap Kualitas Pelayanan dan Jasa Dengan Menggunakan Metode Importance Performance Analysis (Studi Kasus di Restoran Warung Subak, Peguyangan Denpasar.

https://ojs.unud.ac.id/index.php/jtip/article/view/16925. [Diakses 25/4/2018]

Martilla, J.A. and J.C. James, 1977. Importance Performance Analysis. Journal of Marketing. 77-79

Mulyatiningsih, E. 2012. Metode Penelitian Terapan Bidang Pendidikan. CV.Alfabeta, Bandung

Singarimbun, M. dan S. Effendi. 1989. Metode Penelitian Survey. LP3ES, Jakarta.

Sevilla, C. 1993. Pengantar Metode Penelitian. Universitas Indonesia Press, Jakarta.

Windu Wirajaya, Gede. 2017. Analisis Kepuasan Konsumen Terhadap Produk di Bali Tangi Spa. https://ojs.unud.ac.id/index.php/jtip/article/view/25646. [Diakses 25/4/2018] 